\title{
Sulfobacillus thermosulfidooxidans strain Cutipay enhances chalcopyrite bioleaching under moderate thermophilic conditions in the presence of chloride ion
}

\author{
Roberto A Bobadilla-Fazzini ${ }^{* *}$, Maria Paz Cortés ${ }^{2,3}$, Alejandro Maass ${ }^{3,4}$ and Pilar Parada ${ }^{1}$
}

\begin{abstract}
Currently more than $90 \%$ of the world's copper is obtained through sulfide mineral processing. Among the copper sulfides, chalcopyrite is the most abundant and therefore economically relevant. However, primary copper sulfide bioleaching is restricted due to high ionic strength raffinate solutions and particularly chloride coming from the dissolution of ores. In this work we describe the chalcopyrite bioleaching capacity of Sulfobacillus thermosulfidooxidans strain Cutipay (DSM 27601) previously described at the genomic level (Travisany et al. (2012) Draft genome sequence of the Sulfobacillus thermosulfidooxidans Cutipay strain, an indigenous bacterium isolated from a naturally extreme mining environment in Northern Chile. J Bacteriol 194:6327-6328). Bioleaching assays with the mixotrophic strain Cutipay showed a strong increase in copper recovery from chalcopyrite concentrate at $50^{\circ} \mathrm{C}$ in the presence of chloride ion, a relevant inhibitory element present in copper bioleaching processes. Compared to the abiotic control and a test with Sulfobacillus acidophilus DSM 10332, strain Cutipay showed an increase of 42 and 69\% in copper recovery, respectively, demonstrating its high potential for chalcopyrite bioleaching. Moreover, a genomic comparison highlights the presence of the 2-Haloacid dehalogenase predicted-protein related to a potential new mechanism of chloride resistance in acidophiles. This novel and industrially applicable strain is under patent application CL 2013-03335.
\end{abstract}

Keywords: Copper; Chalcopyrite; Bioleaching; Chloride ion; Chloride resistance; Sulfobacillus

\section{Introduction}

According to the Chilean Copper Commission (COCHILCO, 2014), Chile is the largest copper producer where hydrometallurgy represented 33\% of the 2013 local copper production. Copper sulfides processing accounts for more than $90 \%$ of world's production. Among the copper sulfides, chalcopyrite constitutes the vast majority of copper resources and reserves, and therefore represents a mineralogical species of great economical importance (Doebrich 2009).

Within the available hydrometallurgical technologies heap leaching is one of the most used, particularly for copper oxides and secondary copper sulfides. The detection and identification of microorganisms able to live and reproduce under the acidic conditions of the heap

\footnotetext{
* Correspondence: rboba001@biosigma.cl

${ }^{1}$ BioSigma S.A., Parque Industrial Los Libertadores, Lote 106, Colina, Santiago de Chile, Chile

Full list of author information is available at the end of the article
}

leaching process, and moreover the biotechnological innovations related to their potential use as catalysts for primary copper sulfide bioleaching, are topics of major interest. Different studies have shown the enhancing effect of mesophilic (Bobadilla Fazzini et al. 2011), moderate thermophilic (Stott et al. 2003) and thermophilic (Konishi et al. 1999) microorganisms for chalcopyrite dissolution compared to abiotic assays. However, most of these studies were performed under lab-scale ideal conditions, not taking into account industrial-scale process variables such as high ionic strength solutions.

The application of heap bioleaching for copper recovery is severely limited due to fresh-water scarcity as in northern Chile, or the saline drains in Western Australia, due to solutions of high ionic strength and concentrations of elements coming from the ore minerals dissolution such as atacamite $\left(\mathrm{Cu}_{2} \mathrm{Cl}(\mathrm{OH})_{3}\right)$ that releases chloride ions, which are inhibitory for many acidophilic iron-oxidizing microbes. 
In our estimation, during 2013 about 700 million tons of ore with an average copper grade of $0.2 \%$ could not be bioleached worldwide due to the inhibitory effect of high ionic strength raffinate solutions over acidophiles. The most studied acidophilic species is Acidithiobacillus ferrooxidans, and its sensitivity to low chloride concentration has been described long before, attributed to the loss of the cell outer layer integrity (Lawson et al. 1995). In the case of the widely distributed acidophilic species Leptospirillum ferriphilum, ferrous ion biooxidation is completely inhibited by $12 \mathrm{~g} / \mathrm{L}$ chloride (Gahan et al. 2010). Moreover, prolonged exposure to sodium chloride demonstrated no significant adaptation of mixed chemolithotrophic iron-oxidizing cultures, indicating the lack of an acquired resistance through adaptation (Shiers et al. 2005). Nevertheless, resistant species exist such as Thiobacillus prosperus, a halotolerant acidophile that requires chloride for growth (Nicolle et al. 2009) or the marine Sulfobacillus sp. TPY able to tolerate $2 \%(\mathrm{w} / \mathrm{v})$ $\mathrm{NaCl}$ (Wang et al. 2012).

With respect to the biochemical mechanism of bacterial chloride resistance, few studies are available particularly on acidophiles. A recent study showed that $\mathrm{NaCl}$ stress in the moderate thermophiles Acidimicrobium ferrooxidans and Acidithiobacillus caldus is tackled by cell membrane adaptation and potential osmoprotectant aminoacid accumulation (Zammit et al. 2012), giving an insight on specific chloride resistance genes.

Based on these facts, a search for chloride resistant iron-oxidizing acidophilic strains is a relevant research topic. In this study we describe the chalcopyrite bioleaching capacity of Sulfobacillus thermosulfidooxidans strain Cutipay (DSM 27601) in the presence of chloride ion. Strain Cutipay was previously described with novel copper and arsenic resistance capacities at the genomic level (Travisany et al. 2012).

\section{Material and methods}

\section{Strains and culture conditions}

Sulfobacillus thermosulfidooxidans DSM 27601 strain Cutipay was isolated from an ore deposit in northern Chile. Sulfobacillus acidophilus DSM 10332 was obtained from the DSMZ collection. Both strains were cultivated in shake flasks at $50^{\circ} \mathrm{C}$ in $9 \mathrm{~K}$ medium at pH 1.6 (Bobadilla Fazzini et al. 2011), including the addition of $0.25 \mathrm{~g} / \mathrm{L}$ yeast extract for mixotrophic growth on ferrous. Microorganisms were inoculated at $1 \% \mathrm{v} / \mathrm{v}$. The cell number was determined by chamber counting under phase-contrast microscope (Thoma Chamber, depth $0.010 \mathrm{~mm}$ ) with at least four replicate counts.

\section{Minimum inhibitory concentration assays}

Minimum inhibitory concentration assays (MIC) were performed in 6 well plates with $5 \mathrm{~mL}$ of $9 \mathrm{~K}$ medium at
pH 1.6 for mixototrophic growth on ferrous, inoculated with $1,00 \mathrm{E}+07$ cells $/ \mathrm{mL}$ for each strain separately. Assays were incubated with agitation at $50^{\circ} \mathrm{C}$ for $5 \mathrm{~d}$ with a top film to prevent evaporation. Different concentrations of chloride (tested as $\mathrm{NaCl}$ or $\mathrm{KCl}$ ), $\mathrm{Cu}(\mathrm{II}$ ) (added as $\mathrm{CuSO}_{4}$ ) and $\mathrm{As}(\mathrm{III})$ (added as $\mathrm{As}_{2} \mathrm{O}_{3}$ ) were tested. The lowest concentration at which no growth or iron oxidation was observed corresponds to the MIC that were assayed at least in triplicate.

\section{In silico determination of orthologous protein clusters}

The genome sequences and annotation of the predicted proteomes for Sulfobacillus acidophilus DSM10332 (GenBank IDs:NC_016884.1 and NC_016888.1) and Sulfobacillus sp. TPY (GenBank ID:NC_015757.1) were obtained from the GenBank database. For Sulfobacillus thermosulfidooxidans strain Cutipay, predicted proteome sequence was obtained from an in-house annotation of its genome (GenBank ID: ALWJ01000000) as described previously (Travisany et al. 2012). Using these three predicted proteomes, orthologous protein clusters were determined using ORTHOMCL v1.4 (Li et al. 2003) with default parameters.

\section{Bioleaching tests}

Bioleaching tests were done in shake flasks, as a minimum in duplicate. Each flask contained $100 \mathrm{~mL} 9 \mathrm{~K}$ medium ( $\mathrm{pH}$ 1.6), as described above, and supplemented with $1.5 \mathrm{~g} / \mathrm{L} \mathrm{Fe}(\mathrm{III})$ and $2.5 \mathrm{~g} / \mathrm{L} \mathrm{Fe}(\mathrm{II})$ with $1 \% \mathrm{w} / \mathrm{v} 300$ Tyler mesh sieved chalcopyrite concentrate $(85.5 \%$ chalcopyrite representing more than $99 \%$ of total $\mathrm{Cu}$ in the assay (Additional file 1: Table S1)) and $3 \mathrm{~g} / \mathrm{L}$ chloride (as sodium chloride). Each flask was inoculated with Sulfobacillus thermosulfidooxidans DSM 27601 or Sulfobacillus acidophilus DSM $10332\left(1 \times 10^{7}\right.$ cell $/ \mathrm{mL}$ each). A non-inoculated control was included. Shake flasks were incubated for $27 \mathrm{~d}$ at $50^{\circ} \mathrm{C}$ with $120 \mathrm{rpm}$ agitation. Each week cell number, Fe(II) by $o$-phenantroline method, total iron and $\mathrm{Cu}$ (II) by atomic absorption spectrometry were assayed. Sampling was performed allowing the suspended concentrate to settle, and filtering the supernatant to avoid any solids (Grade 5C filters, Advantec, Japan). Evaporation was compensated with pure water before each sampling time.

\section{Results}

In order to determine the phenotypic properties of Sulfobacillus thermosulfidooxidans strain Cutipay (DSM 27601) related to heavy metals and chloride resistance, MIC assays were performed and compared to a collection Sulfobacillus strain. The results are summarized in Table 1.

Significant differences in chloride MIC using sodium or potassium salts were observed, requiring two to three 
Table 1 Minimum Inhibitory Concentrations (MIC) for inhibitory elements chloride, copper and arsenic

\begin{tabular}{lllll}
\hline $\begin{array}{l}\text { Moderate thermophilic } \\
\text { species }\end{array}$ & $\begin{array}{l}\text { Chloride } \\
\text { (KCl) } \\
\text { [ppm] }\end{array}$ & $\begin{array}{l}\text { Chloride } \\
\text { (NaCl) }\end{array}$ & $\begin{array}{l}\text { Cu } \\
\text { (II) }\end{array}$ & $\begin{array}{l}\text { As } \\
\text { (III) }\end{array}$ \\
\hline $\begin{array}{l}\text { Sulfobacillus thermosulfidooxidans } \\
\text { Cutipay (DSM 27601) }\end{array}$ & 10,000 & 5,000 & 3,000 & $<100$ \\
$\begin{array}{l}\text { Sulfobacillus acidophilus } \\
\text { (DSM 10332) }\end{array}$ & 3,000 & 1,000 & 1,000 & 1,000 \\
\hline
\end{tabular}

times of potassium chloride to reach total inhibition compared to the sodium salt. Cutipay showed a higher resistance to chloride (three to five times depending the counter-ion used) and copper (three times) and a lower resistance to arsenic (ten times) compared to Sulfobacillus acidophilus DSM 10332. To understand these phenotypes, a whole genome comparison of selected Sulfobacillus species was performed looking for specific chloride resistance genes. The genomes of Sulfobacillus thermosulfidooxidans strain Cutipay and Sulfobacillus sp. TPY, as representatives of chloride-resistant species, were compared together and against Sulfobacillus acidophilus DSM10332, a chloride sensitive strain (Figure 1).

The three strains have 2061 of coded proteins in common. An exclusive cluster of 22 proteins was shared between both chloride resistant strains. An interesting protein annotated as Haloacid dehalogenase (sequence identifier gi|339628570|ref|YP_004720213.1|) was recognized. This protein belongs to the haloacid dehalogenaselike (HAD) superfamily that includes the 2-Haloacid dehalogenase that catalyzes the dechlorination of small organic chloro-acids.

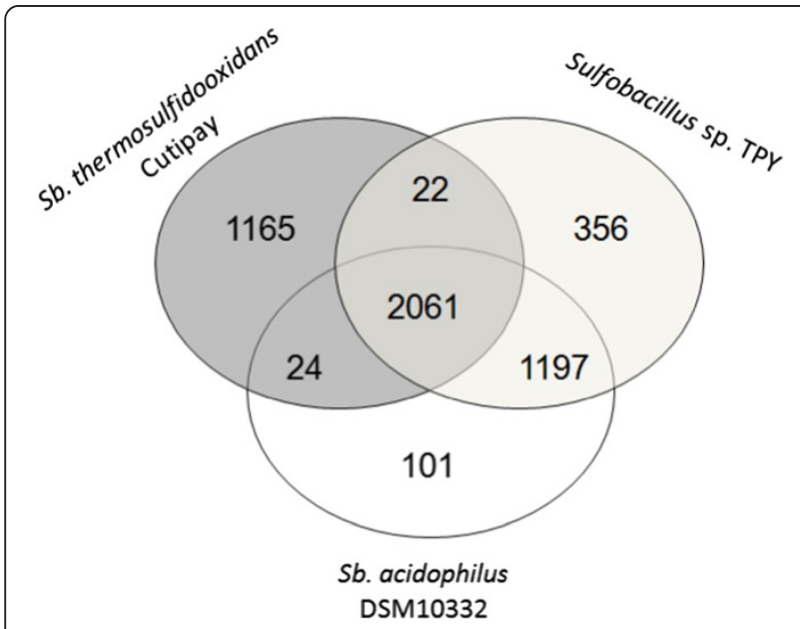

Figure 1 Venn diagram of orthologous genome coded protein clusters for chloride-resistant strains Sulfobacillus sp. TPY and Sulfobacillus thermosulfidooxidans Cutipay, and chloridesensitive strain Sulfobacillus acidophilus DSM 10332. The diagram shows the number of shared and unique clusters between the three strain genomes.
In order to evaluate the relevance of strain Cutipay to enhance chalcopyrite dissolution under process conditions and compare it to the collection strain DSM 10332, chalcopyrite bioleaching tests were done with chloride ion. Copper recovery was periodically measured, showing $31 \%$ copper recovery in the abiotic control at the end of the test. The same effect was observed with Sulfobacillus acidophilus, being lower and reaching 26\% recovery, probably inhibited by chloride ion. However, a strong increase in copper recovery was observed with strain Cutipay despite chloride present. As shown in Figure 2, chalcopyrite bioleaching was enhanced by strain Cutipay from the beginning, finishing at $44 \%$ on day 27. In the comparison with the collection strain Sulfobacillus acidophilus DSM 10332 and the abiotic control assays, strain Cutipay increased copper recovery in 18 and 13 percentage points which represented an increment of 69 and $42 \%$, respectively, demonstrating its high potential for chalcopyrite bioleaching in the presence of chloride ion. Figure 3 shows that Sulfobacillus thermosulfidooxidans Cutipay was able to oxidize ferrous to ferric ions in the presence of chloride ion maintaining a high oxidation reduction potential, while Sulfobacillus acidophilus DSM10332 did not oxidize Fe(II) which is comparable to the control without inoculation. Previous results showed that both species have comparable iron oxidations rates, with same optimum $\mathrm{pH}$ of 1.7 and temperature $\left(51^{\circ} \mathrm{C}\right)$ (Watling et al. 2008), so the observed effect can be attributed only to chloride ion inhibition.

\section{Discussion}

In this study a novel mixotrophic bacterium Sulfobacillus thermosulfidooxidans strain Cutipay (DSM 27601) was characterized for heavy metals and chloride resistance. Sodium and potassium chloride salts were separately used for chloride MIC testing, since the counter-ion

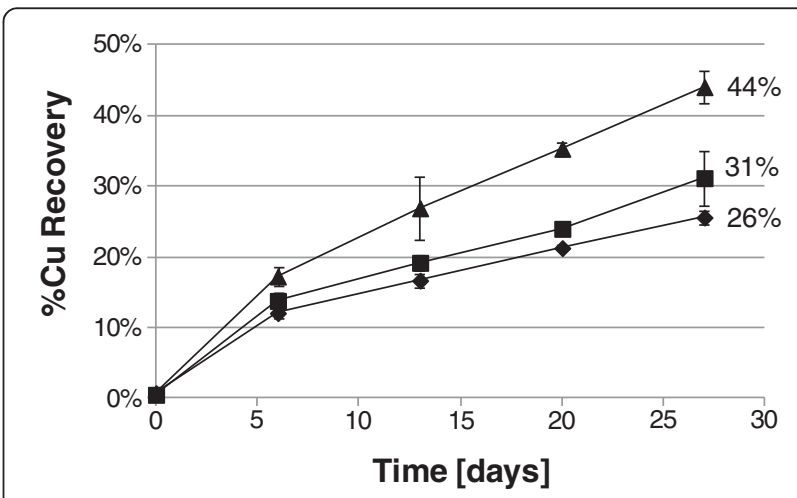

Figure $\mathbf{2}$ Copper recovery in chalcopyrite bioleaching tests in the presence of chloride ion $(3 \mathrm{~g} / \mathrm{L})$, incubation at $50^{\circ} \mathrm{C}$ and addition of Sulfobacillus thermosulfidooxidans DSM 27601 strain Cutipay (A); Sulfobacillus acidophilus DSM 10332 (»). A control

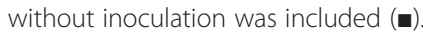



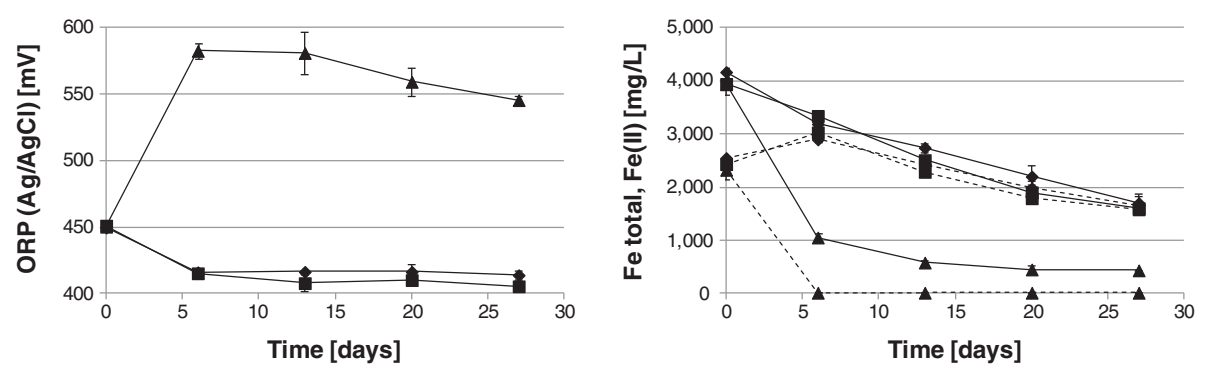

Figure 3 Oxidation Reduction Potential (ORP) (Left panel) and total (continuous lines) and ferrous iron (dotted lines) (Right panel) in chalcopyrite bioleaching assays in the presence of chloride ion $(\mathbf{3} \mathbf{g} / \mathbf{L})$ at $50^{\circ} \mathrm{C}$. Sulfobacillus thermosulfidooxidans DSM 27601 strain Cutipay

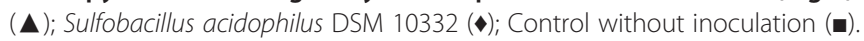

(potassium or sodium) affects the inhibitory effect of anions (Suzuki et al. 1999) and therefore the MIC. These results are only partially in agreement with our previous genomic analyses (Travisany et al. 2012), supporting copper but not arsenic resistance. Sulfobacillus thermosulfidooxidans has been reported to be highly resistant to copper, nickel and zinc, while Sulfobacillus acidophilus to cobalt (Watling et al. 2008). Sulfobacillus thermosulfidooxidans DSM9293 isolated from an ore deposit in Eastern Kazakhstan has been tested for sodium chloride resistance, starting to show inhibition at $7 \mathrm{~g} / \mathrm{L}$ ( $4 \mathrm{~g}$ chloride/L) (Zammit et al. 2012), while Sulfobacillus sp. TPY found in an hydrothermal vent in the Pacific Ocean grows in the presence of $20 \mathrm{~g} / \mathrm{L} \mathrm{NaCl}(12 \mathrm{~g}$ chloride/L) (Wang et al. 2012). In this study Sulfobacillus thermosulfidooxidans Cutipay from an ore deposit in Chile was completely inhibited at 21 and $8 \mathrm{~g} / \mathrm{L}$ potassium and sodium chloride, respectively, having chloride resistance comparable to previous reports for the same species, but below the marine strain TPY.

Based on the genome comparison, the chloride-resistant representative species have the Haloacid dehalogenase coding gene. Therefore, a possible mechanism of chloride resistance in sulfobacilli may be related to the biodegradation of toxic small chloro-organic acids formed in the presence of chloride, which are produced from the dissolution of gangue material in hydrometallurgical processes (Dopson et al. 2008) that reacts with organic matter such as cell products or debris (Keppler et al. 2000). To our knowledge no chloride resistance mechanism nor related gene has been identified up to date in acidophiles, and therefore this finding may provide new insights into extremophilic microorganisms behavior. On this matter, previous studies have shown the role of membrane and/or amino acid biosynthesis, efflux transporters and $\mathrm{CO}_{2}$ fixation as multifunctional responses to chloride exposure in acidophilic species (Zammit et al. 2012). However these are general osmo-protection mechanisms observed in different microbial species (Zhou et al. 2013; Paul 2013).
Finally, the bioleaching tests showed that strain Cutipay resistance enhances chalcopyrite bioleaching at $50^{\circ} \mathrm{C}$ in the presence of chloride, based on its fast iron-oxidizing activity compared to the chloride sensitive strain Sulfobacillus acidophilus DSM 10332. Here, only in the case of strain Cutipay all the ferrous iron was completely oxidized. However, a major drop in total iron concentration was observed lowering from 4 to $1 \mathrm{~g} / \mathrm{L}$, due to the formation of iron precipitates such as jarosite, as visually observed only on strain Cutipay's inoculated flasks (data not shown). No matter this precipitation and potential surface passivation, chalcopyrite bioleaching enhancement is clearly shown.

Summarizing, in this study a novel mixotrophic bacterium with resistance to chloride was presented, showing a genomic feature related to a potential new mechanism of chloride resistance and proven to enhance chalcopyrite bioleaching at $50^{\circ} \mathrm{C}$ in the presence of chloride, a relevant inhibitory element present in important industrial bioleaching processes.

\section{Additional file}

Additional file 1: Table S1. Chalcopyrite Concentrate mineralogy.

\section{Competing interests}

The authors declare that this work was supported by BioSigma 'S.A.', a profit Research, Development and Innovation Company. Currently, BioSigma 'S.A.' is applying to patent Sulfobacillus thermosulfidooxidans strain Cutipay (DSM 27601) use for bioleaching purposes under the patent application $\mathrm{CL}$ 2013-03335.

\section{Authors' contributions}

RABF designed and undertook the microbiological, characterization and bioleaching studies, and conceived and drafted the manuscript. MPC carried out the In silico determinations. AM design and coordinated the bioinformatics approach. PP participated in the coordination and helped to draft the manuscript. All authors read and approved the final manuscript.

\section{Acknowledgements}

This work was supported by BioSigma 'S.A.'. The authors thank the company for authorizing the submission of the manuscript for publication. We are also grateful to Fondap Grant 15090007, Basal Grant Center for Mathematical Modeling UMI2807 UCHILE-CNRS and the CIRIC-INRIA Chile project. 


\section{Author details}

'BioSigma S.A., Parque Industrial Los Libertadores, Lote 106, Colina, Santiago de Chile, Chile. 'Laboratory of Bioinformatics and Mathematics of the Genome, Center for Mathematical Modeling (UMI2807-CNRS) and FONDAP Center for Genome Regulation, Santiago de Chile, Chile. ${ }^{3}$ Faculty of Mathematical and Physical Sciences, University of Chile, Santiago de Chile, Chile. ${ }^{4}$ Department of Mathematical Engineering, Center for Mathematical Modeling (UMI2807-CNRS) and FONDAP Center for Genome Regulation, Santiago de Chile, Chile.

Received: 29 September 2014 Accepted: 20 November 2014

Published online: 10 December 2014

\section{References}

Bobadilla Fazzini RA, Levican G, Parada P (2011) Acidithiobacillus thiooxidans secretome containing a newly described lipoprotein Licanantase enhances chalcopyrite bioleaching rate. Appl Microbiol Biotechnol 89:771-780, doi:10.1007/s00253-010-3063-8

Chilean Copper Commission (COCHILCO) (2014) Mining production database., http://www.cochilco.cl/estadisticas/produccion.asp. Accessed 18 November 2014

Doebrich J (2009) Copper-a metal for the ages: U.S. geological survey fact sheet 2009-3031., http://pubs.usgs.gov/fs/2009/3031/. Accessed 18 November 2014

Dopson M, Halinen A, Rahunen N, Bostro D, Sundkvist J, Riekkola-vanhanen M, Kaksonen AH, Puhakka JA (2008) Silicate mineral dissolution during heap bioleaching. 99:811-820. doi:10.1002/bit

Gahan CS, Sundkvist J-E, Dopson M, Sandström A (2010) Effect of chloride on ferrous iron oxidation by a Leptospirillum ferriphilum-dominated chemostat culture. Biotechnol Bioeng 106:422-431, doi:10.1002/bit.22709

Keppler F, Eiden R, Niedan V, Pracht J, Schöler HF (2000) Halocarbons produced by natural oxidation processes during degradation of organic matter. Nature 403:298-301

Konishi Y, Asai S, Tokushige M, Suzuki T (1999) Kinetics of the bioleaching of chalcopyrite concentrate by acidophilic thermophile acidianus brierleyi. Biotechnol Prog 15:681-688, doi:10.1021/bp9900662

Lawson EN, Nicholas CJ, Pellat H (1995) The toxic effects of chloride ions on Thiobacillus ferrooxidans. In: Vargas T, Jerez CA, Wiertz JV, Toledo H (eds) Biohydrometall. Process. vol I, Univ. Chile., pp 165-174

Li L, Stoeckert CJ Jr, Roos DS (2003) OrthoMCL : identification of ortholog groups for eukaryotic genomes., pp 2178-2189, doi:10.1101/gr.1224503.candidates

Nicolle JLC, Simmons S, Bathe S, Norris PR (2009) Ferrous iron oxidation and rusticyanin in halotolerant, acidophilic "Thiobacillus prosperus". Microbiology 155:1302-1309, doi:10.1099/mic. 0.023192-0

Paul D (2013) Osmotic stress adaptations in rhizobacteria. J Basic Microbiol 53:101-110, doi:10.1002/jobm.201100288

Shiers DW, Blight KR, Ralph DE (2005) Sodium sulphate and sodium chloride effects on batch culture of iron oxidising bacteria. Hydrometallurgy 80:75-82, doi:10.1016/j.hydromet.2005.07.001

Stott MB, Sutton DC, Watling HR, Franzmann PD (2003) Comparative leaching of chalcopyrite by selected acidophilic bacteria and archaea. Geomicrobiol J 20:215-230, doi:10.1080/01490450390206692

Suzuki I, Lee D, Mackay B, Harahuc L, Oh JK (1999) Effect of various ions, pH, and osmotic pressure on oxidation of elemental sulfur by Thiobacillus thiooxidans. Appl Environ Microbiol 65:5163-5168

Travisany D, Di Genova A, Sepúlveda A, Bobadilla-Fazzini RA, Parada P, Maass A (2012) Draft genome sequence of the Sulfobacillus thermosulfidooxidans Cutipay strain, an indigenous bacterium isolated from a naturally extreme mining environment in Northern Chile. J Bacteriol 194:6327-6328, doi:10.1128/JB.01622-12

Wang Y, Su L, Zhang L, Zeng W, Wu J, Wan L, Qiu G, Chen XZH (2012) Bioleaching of chalcopyrite by defined mixed moderately thermophilic consortium including a marine acidophilic halotolerant bacterium. Bioresour Technol 121:348-354, doi:10.1016/j.biortech.2012.06.114

Watling HR, Perrot FA, Shiers DW (2008) Comparison of selected characteristics of Sulfobacillus species and review of their occurrence in acidic and bioleaching environments. Hydrometallurgy 93:57-65
Zammit CM, Mangold S, Jonna VR, Mutch LA, Watling HR, Dopson M, Watkin ELJ (2012) Bioleaching in brackish waters-effect of chloride ions on the acidophile population and proteomes of model species. Appl Microbiol Biotechnol 93:319-329, doi:10.1007/s00253-011-3731-3

Zhou A, Baidoo E, He Z, Mukhopadhyay A, Baumohl JK, Benke P, Joachimiak MP, Xie M, Song R, Arkin AP, Hazen TC, Keasling JD, Wall JD, Stahl DA, Zhou J (2013) Characterization of $\mathrm{NaCl}$ tolerance in Desulfovibrio vulgaris Hildenborough through experimental evolution. ISME J 7:1790-1802, doi:10.1038/ismej.2013.60

\section{doi:10.1186/s13568-014-0084-1}

Cite this article as: Bobadilla-Fazzini et al.: Sulfobacillus

thermosulfidooxidans strain Cutipay enhances chalcopyrite bioleaching under moderate thermophilic conditions in the presence of chloride ion. AMB Express 2014 4:84

\section{Submit your manuscript to a SpringerOpen ${ }^{\odot}$ journal and benefit from:}

- Convenient online submission

- Rigorous peer review

- Immediate publication on acceptance

- Open access: articles freely available online

- High visibility within the field

- Retaining the copyright to your article

Submit your next manuscript at $>$ springeropen.com 